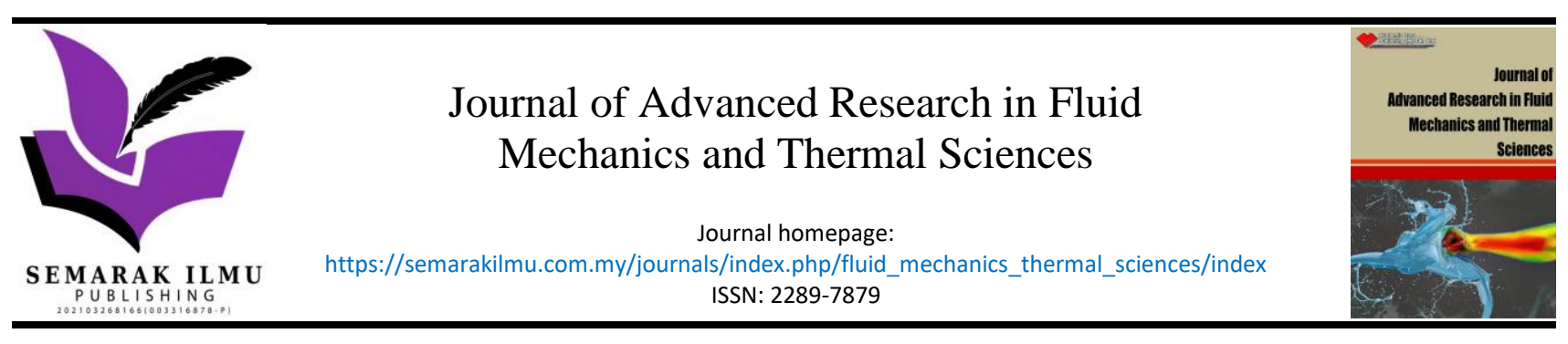

\title{
Double Stratified MHD Stagnation Point Slip Flow Over a Permeable Shrinking/Stretching Surface in A Porous Medium
}

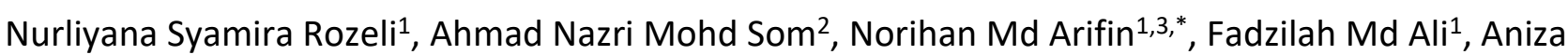 \\ Abd Ghani ${ }^{1}$
}

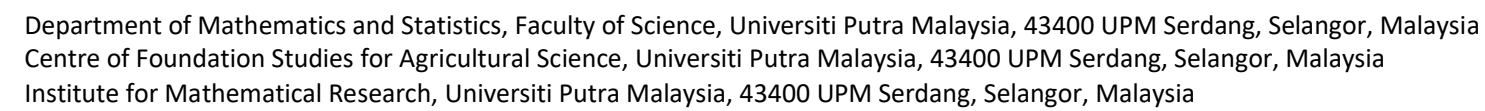

\section{ARTICLE INFO}

Article history:

Received 24 June 2021

Received in revised form 12 December 2021

Accepted 13 December 2021

Available online 2 January 2022

\section{Keywords:}

Boundary layer; Stagnation point slip flow; MHD; Permeable; Porous medium

\section{ABSTRACT}

\begin{abstract}
The intention of this article is to investigate the impact of slip of MHD stagnation point flow over a permeable shrinking/stretching sheet with double stratification in a porous medium. Employing the appropriate similarity transformations and non-dimensional variables, the governing partial differential equations were reduced into a set of nonlinear ordinary differential equations. These equations were solved using shooting method and influence of pertinent variables on velocity, temperature and concentration are computed and analyzed. It was found that the slips have the propensity to control boundary layer flow and as the velocity slip increases, the momentum, thermal, and concentration boundary layer thickness become thinner for velocity slip. Therefore, velocity slip acts as a boost for enhancement of the velocity profile in the boundary layer region, whereas temperature and concentration profiles decelerate with the velocity slip. It is also shown that the skin friction coefficient has decreased as the values of velocity slip increase while the It was found that the slips have the propensity to control boundary layer flow and as the velocity slip increases, the momentum, thermal, and concentration boundary layer thickness become thinner for velocity slip. Therefore, velocity slip acts as a boost for enhancement of the velocity profile in the boundary layer region, whereas temperature and concentration profiles decelerate with the velocity slip. It is also shown that the skin friction coefficient has decreased as the values of velocity slip increase while the local Nusselt number and the local Sherwood number are increasing. A comparison with previous studies available in the literature has been done and found an excellent agreement by comparing the numerical results in two decimal places which supports the validity of the present analysis.
\end{abstract}

\section{Introduction}

Magnetohydrodynamic (MHD) flow of viscous fluid plays an important role in various engineering and industrial processes, for example in nuclear power plants, production of plastic films, hydroelectric power plant and melt spinning process. In recent years, some interest has been given

\footnotetext{
* Corresponding author.

E-mail address: norihana@upm.edu.my
}

https://doi.org/10.37934/arfmts.90.2.6472 
to investigate the flow over a shrinking/stretching sheet, where the sheet is shrunk/stretched toward a slot and it would cause a velocity away from sheet. Many useful studies on boundary layer problem in various geometry in this regard were investigated by Makinde and Animasaun [1], Ramzan et al., [2], Salleh et al., [3], Yahaya et al., [4], Junoh et al., [5], Khashi'ie et al., [6,7], and Wahid et al., [8].

The role of stratification in heat and mass transfer is essential. Stratification depends upon on temperature, concentration differences or existence of fluids with different densities. The applications of stratifications include such as thermal stratification of reservoirs, processing rivers, subterranean water storage manufacturing, different heterogeneous mixtures, industrial foods, ground water reservoirs, condensers of power plants and density stratification of atmosphere. Moreover, the role of thermal stratification is vital in solar engineering as it is the main ingredient to boost the efficiency of the system. Studies highlighting the different aspects of stratification may be quoted in this regard. Mukhopadhyay [9] investigated double stratification on MHD heat and mass transfer fluid flow over exponential stretching surface along with suction. Daniel et al., [10] studied the effects of joule heating and thermal radiation on MHD flow of Casson fluid due to nonlinear stretching sheet embedded by double stratifications. Khashi'ie et al., [11] investigated Magnetohydrodynamic flow and heat transfer characteristics of a dual stratified micropolar fluid over a permeable stretching/shrinking sheet where the thermal and solutal buoyancy forces are also included to incorporate with the stratification effect. The stagnation point flow of hybrid nanofluid over a permeable vertical stretching/shrinking cylinder with thermal stratification effect was analyzed Khashi'ie et al., [12]. Recently, Khashi'ie et al., [13] investigated the MHD stagnation point flow pasts a stretching/shrinking surface in a porous medium and include the effects of double stratification. They calculated dual solutions by solving self-similar governing equations and found that range of dual solutions increases and decreases by considering the effects of stretching/shrinking surface. The stability analysis for dual solutions has been performed and they showed that the first solutions are physically significant, and the second solutions are not reliable physically.

The slip effect cannot be ignored especially in the flow of non- Newtonian fluids. Polishing of artificial heart valves, melting of polymer and internal cavities are some utilizations of boundary slip. Beavers and Joseph [14] investigated the fluid flow over a permeable wall using slip boundary condition. The slip flows under different flow configurations have been studied by many researchers [15-19] in recent years. In this study, we extended the work of Khashi'ie et al., [13] by investigating the effects of velocity slip condition with permeable shrinking/stretching surface. The governing equations of the fluid flow are solved numerically, and the influences of variable flow physical parameters are discussed graphically. The results are validated through the comparison study made with the available results in the literature.

\section{Mathematical Formulation}

Consider a steady, laminar, two-dimensional mixed convective stagnation point flow of an incompressible viscous fluid towards a vertical stretching/shrinking sheet saturated in a porous medium as shown in Figure 1. A uniform magnetic field of strength $B_{0}$ is applied normal to the sheet with the presence of heat source effect. The variable wall temperature and concentration are $T_{w}(x)=T_{\infty, 0}+A x$ and $C_{w}(x)=C_{\infty, 0}+E x$ where $A$ and $E$ are constants while $T_{w}>T_{\infty, 0}$ and $C_{w}>$ $C_{\infty, 0}$. The ambient temperature and concentration are assumed to be linearly stratified in the form of $T_{\infty}(x)=T_{\infty, 0}+B x$ and $C_{\infty}(x)=C_{\infty, 0}+F x$, respectively, where $B$ and $F$ are constants and varied to alter the intensity of stratification while $T_{(\infty, 0)}$ and $C_{(\infty, 0)}$ are the initial ambient or reference temperature and concentration. $U_{w}(x)=a x$ and $U_{e}(x)=b x$ are the stretching/shrinking velocity 
and free stream velocity, respectively, where $a>0$ for stretching sheet, $a<0$ for shrinking sheet and $b$ is a positive constant.

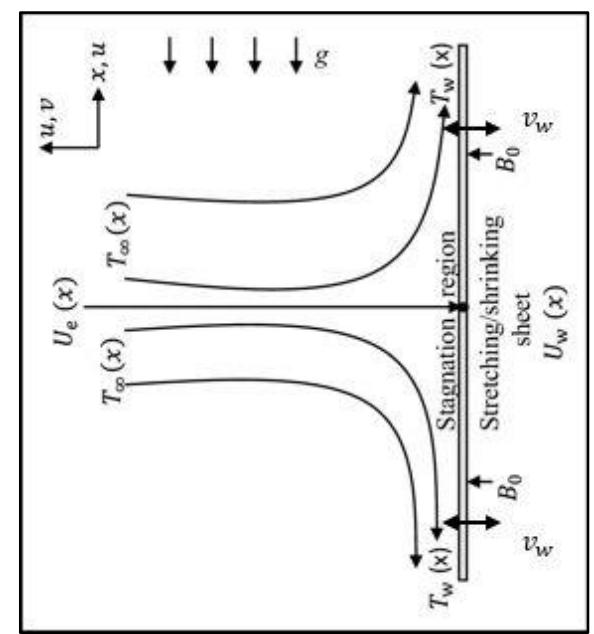

Fig. 1. The physical model and coordinate system

Under these assumptions and the boundary layer approximation, the governing equations are:

$\frac{\partial u}{\partial x}+\frac{\partial v}{\partial y}=0$

$u \frac{\partial u}{\partial x}+v \frac{\partial u}{\partial y}=U_{e} \frac{d U_{e}}{d x}+v \frac{\partial^{2} u}{\partial y^{2}}-\left(\frac{\sigma B_{0}^{2}}{\rho}+\frac{v}{k_{1}}\right)\left(u-U_{e}\right)+g\left[\beta_{T}\left(T-T_{\infty}\right)+\beta_{C}\left(C-C_{\infty}\right)\right]$,

$u \frac{\partial T}{\partial x}+v \frac{\partial T}{\partial y}=\alpha \frac{\partial^{2} T}{\partial y^{2}}+\frac{Q}{\rho C_{p}}\left(T-T_{\infty}\right)$

$u \frac{\partial C}{\partial x}+v \frac{\partial C}{\partial y}=D \frac{\partial^{2} C}{\partial y^{2}}$

with boundary conditions

$$
\begin{aligned}
& u(x, 0)=a x+s \frac{\partial u}{\partial y}, \quad v(x, 0)=v_{w}, \\
& T(x, 0)=T_{w}(x), \quad C(x, 0)=C_{w}(x), \\
& u(x, y) \rightarrow U_{e}(x)=b x, \quad T(x, y) \rightarrow T_{\infty}(x), \\
& C(x, y) \rightarrow C_{\infty}(x) \text { as } \quad y \rightarrow \infty,
\end{aligned}
$$

where $(u, v)$ are the velocity components along the $(x, y)$ axes, respectively, $s$ is the slip length, $v_{w}$ is the velocity of suction $\left(v_{w}>0\right)$ or injection $\left(v_{w}<0\right), T$ is the fluid temperature, $v$ is the kinematic viscosity, $\sigma$ is the electrical conductivity of the fluid, $\rho$ is the fluid density, $B_{0}$ is the strength of the magnetic field, $k_{1}$ is the permeability of the porous medium, $g$ is the gravitational acceleration, $\beta_{T}$ is the coefficient of thermal expansion, $\beta_{C}$ is the coefficient of concentration expansion, $\alpha$ is the thermal diffusivity, $Q$ is the dimensional heat generation coefficient, $C_{p}$ is the specific heat of fluid and $D$ is the mass diffusivity.

The following similarity transformation has been introduced to transform Eq. (1) to Eq. (4) subject to the boundary conditions (5) into a system of ordinary differential equation. 
$\eta=\sqrt{\frac{U_{e}}{v x}} y, \quad \psi=\sqrt{U_{e} v x f(\eta)}, \quad \theta(\eta)=\frac{T-T_{\infty}(x)}{T_{w}(x)-T_{\infty, 0}}, \quad \phi(\eta)=\frac{C-C_{\infty}(x)}{C_{w}(x)-C_{\infty, 0}}$,

where $\eta$ is the similarity variable and $\psi$ is the stream function such that

$u=\frac{\partial \psi}{\partial y}$ and $v=-\frac{\partial \psi}{\partial x}$

which satisfies (1). Using (5),

$u=b x f^{\prime}(\eta)$ and $v=-\sqrt{b v} f(\eta)$.

Using the above similarity transformation, the governing Eq. (1) to Eq. (4) are reduced into the nonlinear differential equations as follows:

$f^{\prime \prime \prime}+f f^{\prime \prime}-\left(f^{\prime}\right)^{2}+(M+K)\left(1-f^{\prime}\right)+1+\lambda \theta+N \phi=0$,

$\theta^{\prime \prime}+\operatorname{Pr}\left(f \theta^{\prime}-f^{\prime} \theta-\delta_{1} f^{\prime}+S \theta\right)=0$

$\phi^{\prime \prime}+S c\left(f \phi^{\prime}-f^{\prime} \phi-\delta_{2} f^{\prime}\right)=0$,

with boundary conditions

$f(0)=f_{w}, f^{\prime}(0)=\varepsilon+\gamma f^{\prime \prime}(0), \theta(0)=1-\delta_{1}, \phi(0)=1-\delta_{2}$,

$f^{\prime}(\eta) \rightarrow 1, \theta(\eta) \rightarrow 0, \phi(\eta) \rightarrow 0$, as $\eta \rightarrow \infty$,

where primes denote differentiation with respect to similarity variable $\eta, M=\left(\frac{\sigma B_{0}^{2}}{\rho b}\right)$ is the magnetic field parameter, $K=\frac{v}{k_{1} b}$ is the porous parameter, $\lambda=\frac{G r}{R e_{x}^{2}}$ is the thermal buoyancy parameter, $N=$ $\frac{G r^{*}}{R e_{x}^{2}}$ is the solutal buoyancy parameter, $G r=\frac{g \beta_{T}\left(T_{w}(x)-T_{\infty, 0}\right) x^{3}}{v^{2}}$ is the local Grashof number due to temperature, $G r^{*}=\frac{g \beta_{C}\left(C_{w}(x)-C_{\infty, 0}\right) x^{3}}{v^{2}}$ is the local Grashof number due to concentration, $\operatorname{Re}=\frac{x U_{e}(x)}{v}$ is the local Reynolds number, $\operatorname{Pr}=\frac{v}{\alpha}$ is the Prandtl number, $\delta_{1}=\frac{B}{A}$ is the thermal stratification parameter, $S=\frac{Q}{\rho b C_{p}}$ is the heat generation coefficient, $S c=\frac{v}{D}$ is the Schmidt number and $\delta_{2}=\frac{F}{E}$ is the solutal stratification parameter. Meanwhile $f_{w}$ be the mass flux parameter, for suction parameter $\left(f_{w}>0\right)$ and for injection parameter $\left(f_{w}<0\right)$, and $\varepsilon$ is the velocity ratio parameter $(\varepsilon>$ 0 and $\varepsilon<0$ ) correspond to the stretching and shrinking parameters, respectively, and $\gamma$ is the slip parameter. The physical quantities that are used in the present study are the skin friction coefficient, local Nusselt number and local Sherwood number which are defined as

$C_{f}=\frac{\tau_{w}}{\rho U_{e}^{2}}, \quad N u_{x}=\frac{x q_{w}}{k\left(T_{w}(x)-T_{\infty, 0}\right)}, \quad S h_{x}=\frac{x q_{m}}{D\left(C_{w}(x)-C_{\infty, 0}\right)}$,

respectively, where $\tau_{w}$ is the wall shear stress along the stretching/shrinking surface, $q_{w}$ is the surface heat flux and $q_{m}$ is the surface mass flux; 


$$
\tau_{w}=\mu\left(\frac{\partial u}{\partial y}\right)_{y=0}, \quad q_{w}=-k\left(\frac{\partial T}{\partial y}\right)_{y=0}, \quad q_{m}=-D\left(\frac{\partial C}{\partial y}\right)_{y=0} .
$$

The local skin friction coefficient, local Nusselt and local Sherwood numbers in the dimensionless forms are given by

$$
C_{f} R e_{x}^{\frac{1}{2}}=f^{\prime \prime}(0), \frac{N u_{x}}{R e_{x}^{\frac{1}{2}}}=-\theta^{\prime}(0), \frac{S h_{x}}{R e_{x}^{\frac{1}{2}}}=-\phi^{\prime}(0) .
$$

\section{Results and Discussion}

The system of nonlinear ordinary differential equations (9) to (11) subject to the boundary conditions (12) is numerically solved using shooting method in MAPLE software.

The results highlight the influences of the suction/injection parameter $f_{w}$, porous parameter $K$ and slip parameter $\gamma$ on the velocity, temperature and concentration profiles as well as the skin friction coefficient, the local Nusselt and Sherwood numbers. All the profiles (see Figure 5 to Figure 7) have asymptotically satisfied the far field boundary conditions, and a comparison also has been made with the earlier published results as tabulated in Table 1 in order to validate the accuracy of the present numerical method. The results numerically confirm that there occur dual solutions for this problem. It was found that the results were in good agreement with Khashi'ie et al., [13]. The stability analysis of dual solutions is done by Khashi'ie et al., [13] to determine the stability and significance of the dual solutions. Therefore, the stability analysis is not repeated for this problem. For previous study by Khashi'ie et al., [13], the numerical computations were solved using boundary value problem solver (bvp4c) in the MATLAB software whereas this present study using shooting method in MAPLE software. For the porous parameter, $K \neq 0$ corresponds to the stretching/shrinking sheet in a porous medium saturated with viscous fluid. The values of $S=N=$ $1, \delta_{1}=\delta_{2}=0.01, M=2.25, \varepsilon=0.5, \lambda=-1, \operatorname{Pr}=0.72$ and $S c=0.78$ are used in this computation.

\begin{tabular}{|c|c|c|c|c|c|c|}
\hline \multirow[t]{2}{*}{$K$} & \multicolumn{3}{|c|}{ Khashi'ie et al., [13] } & \multicolumn{3}{|l|}{ Present } \\
\hline & $f^{\prime \prime}(0)$ & $-\theta^{\prime}(0)$ & $-\phi^{\prime}(0)$ & $f^{\prime \prime}(0)$ & $-\theta^{\prime}(0)$ & $-\phi^{\prime}(0)$ \\
\hline 0 & $\begin{array}{l}0.98281 \\
(0.12380)\end{array}$ & $\begin{array}{l}0.50668 \\
(-3.10283)\end{array}$ & $\begin{array}{l}0.95437 \\
(0.64942)\end{array}$ & $\begin{array}{l}0.98140 \\
(0.12360)\end{array}$ & $\begin{array}{l}0.49964 \\
(-3.10472)\end{array}$ & $\begin{array}{l}0.95310 \\
(0.64849)\end{array}$ \\
\hline 0.1 & $\begin{array}{l}0.99565 \\
(0.13670)\end{array}$ & $\begin{array}{l}0.50811 \\
(-3.18521)\end{array}$ & $\begin{array}{l}0.95532 \\
(0.65043)\end{array}$ & $\begin{array}{l}0.99453 \\
(0.13643)\end{array}$ & $\begin{array}{l}0.50252 \\
(-3.18743)\end{array}$ & $\begin{array}{l}0.95438 \\
(0.64945)\end{array}$ \\
\hline 0.5 & $\begin{array}{l}1.04540 \\
(0.18676)\end{array}$ & $\begin{array}{l}0.51347 \\
(-3.51550)\end{array}$ & $\begin{array}{l}0.95891 \\
(0.65429)\end{array}$ & $\begin{array}{l}1.04429 \\
(0.18623)\end{array}$ & $\begin{array}{l}0.50738 \\
(-3.51911)\end{array}$ & $\begin{array}{l}0.95788 \\
(0.65316)\end{array}$ \\
\hline 1 & $\begin{array}{l}1.10440 \\
(0.24619)\end{array}$ & $\begin{array}{l}0.51945 \\
(-3.93015)\end{array}$ & $\begin{array}{l}0.96296 \\
(0.65878)\end{array}$ & $\begin{array}{l}1.10341 \\
(0.24539)\end{array}$ & $\begin{array}{l}0.51343 \\
(-3.93537)\end{array}$ & $\begin{array}{l}0.96195 \\
(0.65749)\end{array}$ \\
\hline
\end{tabular}

Table 1

The effect of the skin friction coefficient, local Nusselt and Sherwood numbers towards the slip parameter $\gamma$ for selected values of $f_{w}$ are represented as shown in Figure 2 to Figure 4 . The graphs display that the dual solutions are exists and denoted by solid and dashed line for first and second solutions, respectively. The skin friction coefficient, local Nusselt and Sherwood number against slip parameter $\gamma$ for first solution increase when $f_{w}$ increases $\left(f_{w}=-1.0,0,1.0\right)$. 


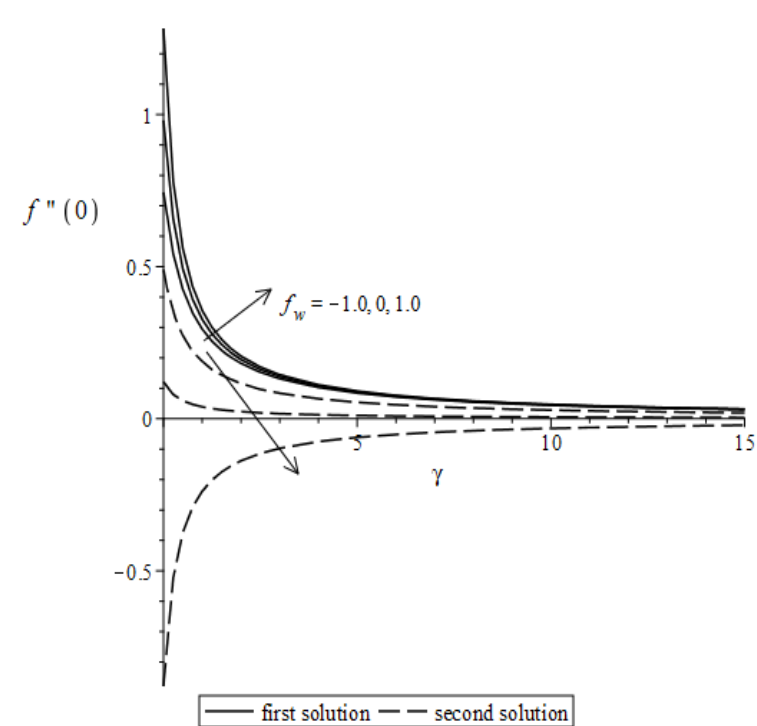

Fig. 2. Variations of the skin friction coefficient, $f^{\prime \prime}(0)$ towards $\gamma$ for selected values of $f_{w}$ when $K=0$

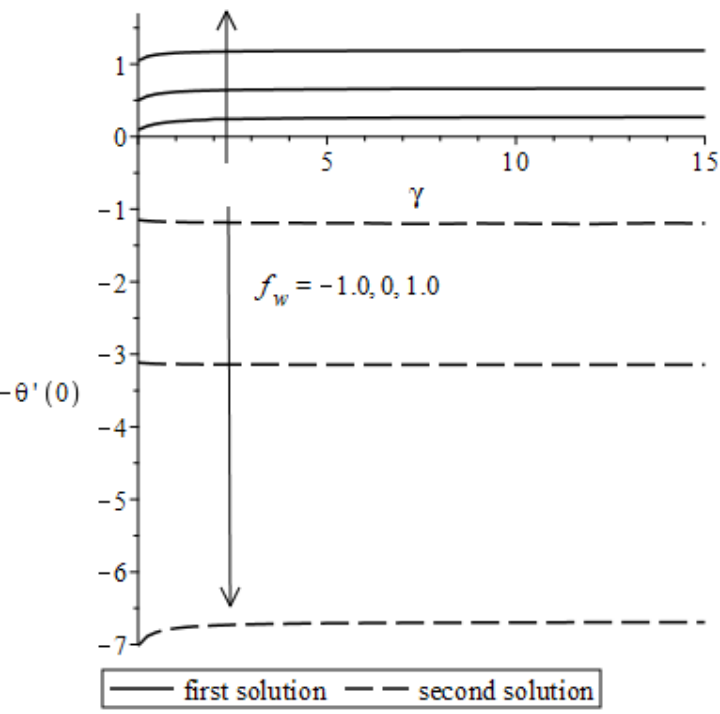

Fig. 3. Variations of the local Nusselt number, $-\theta^{\prime}(0)$ towards $\gamma$ for selected values of $f_{w}$ when $K=0$

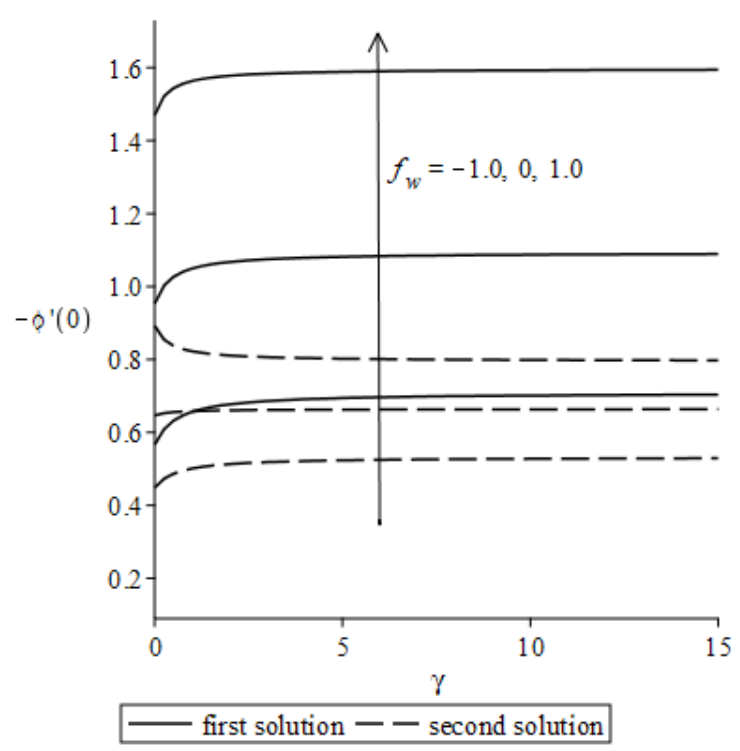

Fig. 4. Variations of the local Sherwood number, $-\phi^{\prime}(0)$ towards $\gamma$ for selected values of $f_{w}$ when $K=0$

For second solution, the graphs of skin friction coefficient, local Nusselt and Sherwood numbers show opposite trend for $f_{w}<0$ and $f_{w}>0$. Figure 5 to Figure 7 portray the impacts of the slip parameter $\gamma$ on the velocity, temperature and concentration profiles when value $f_{w}=-1.0$. During injection, the velocity profile indicates an increment whereas temperature and concentration profiles decline with the enhancement of the slip parameter $(\gamma=0,2.0,5.0)$ for first solution. The flow penetration into the fluid becomes shorter for smaller value of $\gamma$ during injection. For second solution, as $\gamma$ deflates, the velocity and concentration profiles increase while $\gamma$ increases as temperature profile increases. 


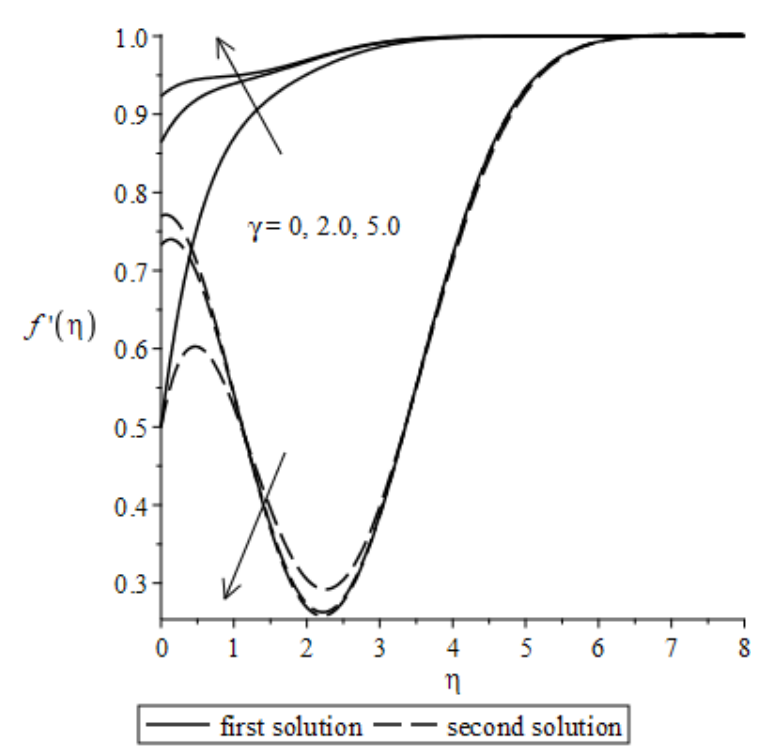

Fig. 5. Velocity profile with different values of slip parameter $\gamma$ during injection $\left(f_{w}=-1.0\right)$ and $K=0$



Fig. 6. Temperature profile with different values of slip parameter $\gamma$ during injection $\left(f_{w}=-1.0\right)$ and $K=0$

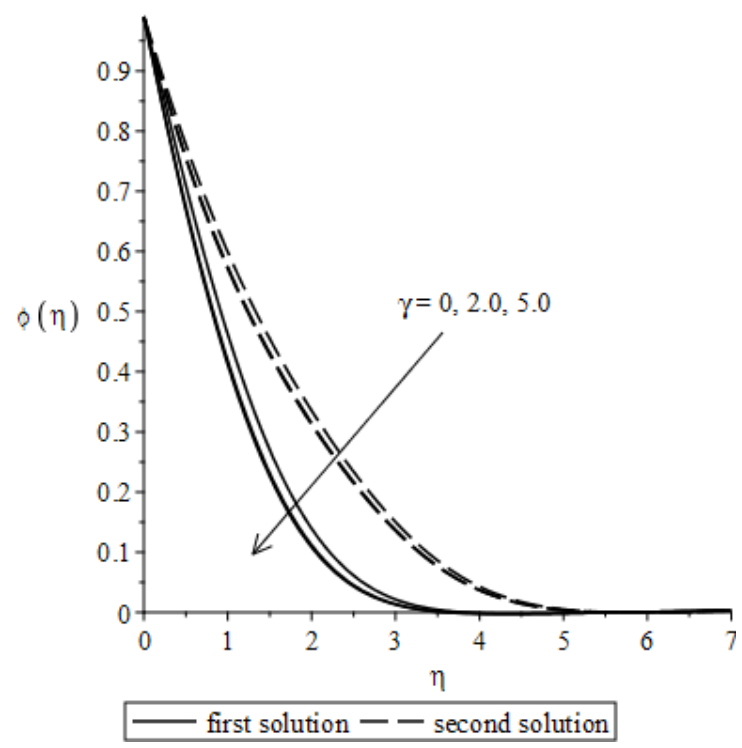

Fig. 7. Concentration profile with different values of slip parameter $\gamma$ during injection $\left(f_{w}=-1.0\right)$ and $K=0$

\section{Conclusions}

This present work deals with the MHD stagnation point flow over a permeable stretching/shrinking surface with double stratification and velocity slip condition. The governing partial differential equations are reduced and transformed into a system of nonlinear ordinary differential equations using similarity transformations. The numerical solutions were obtained using shooting method (MAPLE) and can be concluded that the dual solutions are exists for graphs of skin friction, heat and mass transfer rates against slip parameters. The skin friction coefficient, heat and mass transfer increase as the suction/injection parameter increases for the first solution and show different trend when $f_{w}>0$ and $f_{w}<0$ for the second solution against $\gamma$. Fluid velocity shows an increment for the first solution and decreases for the second solution with the increasing slip 
parameter. The fluid temperature enhances as the slip parameter decreases for the first solution and deflates for the second solution. Fluid concentration increases when the slip parameter decreases for both solutions.

\section{Acknowledgement}

The authors gratefully acknowledge Universiti Putra Malaysia and the financial support given by Ministry of Higher Education Malaysia through the Fundamental Research Grant Scheme (KPTFRGS/1/2019/STG06/UPM/02/3, Vot 5540309).

\section{References}

[1] Makinde, O. D., and I. L. Animasaun. "Thermophoresis and Brownian motion effects on MHD bioconvection of nanofluid with nonlinear thermal radiation and quartic chemical reaction past an upper horizontal surface of a paraboloid of revolution." Journal of Molecular Liquids $221 \quad$ (2016): $733-743$. https://doi.org/10.1016/i.molliq.2016.06.047

[2] Ramzan, Muhammad, Jae Dong Chung, and Naeem Ullah. "Partial slip effect in the flow of MHD micropolar nanofluid flow due to a rotating disk-A numerical approach." Results in Physics 7 (2017): 3557-3566. https://doi.org/10.1016/i.rinp.2017.09.002

[3] Salleh, Siti Nur Alwani, Norfifah Bachok, Norihan Md Arifin, Fadzilah Md Ali, and loan Pop. "Magnetohydrodynamics flow past a moving vertical thin needle in a nanofluid with stability analysis." Energies 11, no. 12 (2018): 3297. https://doi.org/10.3390/en11123297

[4] Yahaya, Rusya Iryanti, Norihan Md Arifin, and Siti Suzilliana Putri Mohamed Isa. "Stability analysis of MHD Carreau fluid flow over a permeable shrinking sheet with thermal radiation." Sains Malaysiana 48, no. 10 (2019): $2285-$ 2295. https://doi.org/10.17576/jsm-2019-4810-25

[5] Junoh, Mohamad Mustaqim, Fadzilah Md Ali, Norihan Md Arifin, Norfifah Bachok, and loan Pop. "MHD stagnationpoint flow and heat transfer past a stretching/shrinking sheet in a hybrid nanofluid with induced magnetic field." International Journal of Numerical Methods for Heat \& Fluid Flow 30, no. 3 (2019): 1345-1364. https://doi.org/10.1108/HFF-06-2019-0500

[6] Khashi'ie, Najiyah Safwa, Norihan Md Arifin, Ezad Hafidz Hafidzuddin, and Nadihah Wahi. "Thermally stratified flow of $\mathrm{Cu}-\mathrm{Al}_{2} \mathrm{O}_{3}$ /water hybrid nanofluid past a permeable stretching/shrinking circular cylinder." Journal of Advanced Research in Fluid Mechanics and Thermal Sciences 63, no. 1 (2019): 154-163.

[7] Khashi'ie, Najiyah Safwa, Norihan Md Arifin, Roslinda Nazar, Ezad Hafidz Hafidzuddin, Nadihah Wahi, and loan Pop. "A stability analysis for magnetohydrodynamics stagnation point flow with zero nanoparticles flux condition and anisotropic slip." Energies 12, no. 7 (2019): 1268. https://doi.org/10.3390/en12071268

[8] Wahid, Nur Syahirah, Norihan Md Arifin, Mustafa Turkyilmazoglu, Mohd Ezad Hafidz Hafidzuddin, and Nor Aliza Abd Rahmin. "MHD hybrid $\mathrm{Cu}-\mathrm{Al}_{2} \mathrm{O}_{3}$ /water nanofluid flow with thermal radiation and partial slip past a permeable stretching surface: analytical solution." In Journal of Nano Research, vol. 64, pp. 75-91. Trans Tech Publications Ltd, 2020. https://doi.org/10.4028/www.scientific.net/JNanoR.64.75

[9] Mukhopadhyay, Swati. "MHD boundary layer flow and heat transfer over an exponentially stretching sheet embedded in a thermally stratified medium." Alexandria Engineering Journal 52, no. 3 (2013): 259-265. https://doi.org/10.1016/i.aej.2013.02.003

[10] Daniel, Yahaya Shagaiya, Zainal Abdul Aziz, Zuhaila Ismail, and Faisal Salah. "Effects of thermal radiation, viscous and Joule heating on electrical MHD nanofluid with double stratification." Chinese Journal of Physics 55, no. 3 (2017): 630-651. https://doi.org/10.1016/i.cjph.2017.04.001

[11] Khashi'ie, Najiyah Safwa, Norihan Md Arifin, Roslinda Nazar, Ezad Hafidz Hafidzuddin, Nadihah Wahi, and Ioan Pop. "Mixed convective flow and heat transfer of a dual stratified micropolar fluid induced by a permeable stretching/shrinking sheet." Entropy 21, no. 12 (2019): 1162. https://doi.org/10.3390/e21121162

[12] Khashi'ie, Najiyah Safwa, Ezad Hafidz Hafidzuddin, Norihan Md Arifin, and Nadihah Wahi. "Stagnation point flow of hybrid nanofluid over a permeable vertical stretching/shrinking cylinder with thermal stratification effect." CFD Letters 12, no. 2 (2020): 80-94.

[13] Khashi'ie, Najiyah Safwa, Norihan Md Arifin, Mohammad Mehdi Rashidi, Ezad Hafidz Hafidzuddin, and Nadihah Wahi. "Magnetohydrodynamics (MHD) stagnation point flow past a shrinking/stretching surface with double stratification effect in a porous medium." Journal of Thermal Analysis and Calorimetry 139, no. 6 (2020): 36353648. https://doi.org/10.1007/s10973-019-08713-8

[14] Beavers, Gordon S., and Daniel D. Joseph. "Boundary conditions at a naturally permeable wall." Journal of Fluid Mechanics 30, no. 1 (1967): 197-207. https://doi.org/10.1017/S0022112067001375 
[15] Khan, Muhammad ljaz, Muhammad Tamoor, Tasawar Hayat, and Ahmed Alsaedi. "MHD boundary layer thermal slip flow by nonlinearly stretching cylinder with suction/blowing and radiation." Results in Physics 7 (2017): 12071211. https://doi.org/10.1016/j.rinp.2017.03.009

[16] Ellahi, Rahmat, Sultan Z. Alamri, Abdul Basit, and A. Majeed. "Effects of MHD and slip on heat transfer boundary layer flow over a moving plate based on specific entropy generation." Journal of Taibah University for Science 12, no. 4 (2018): 476-482. https://doi.org/10.1080/16583655.2018.1483795

[17] Sadiq, Muhammad Adil. "MHD stagnation point flow of nanofluid on a plate with anisotropic slip." Symmetry 11, no. 2 (2019): 132. https://doi.org/10.3390/sym11020132

[18] Adnan, Nurul Shahirah Mohd, Norihan Md Arifin, Norfifah Bachok, and Fadzilah Md Ali. "Stability analysis of MHD flow and heat transfer passing a permeable exponentially shrinking sheet with partial slip and thermal radiation." CFD Letters 11, no. 12 (2019): 34-42.

[19] Abu Bakar, Shahirah, Norihan Md Arifin, Najiyah Safwa Khashi'ie, and Norfifah Bachok. "Hybrid Nanofluid Flow over a Permeable Shrinking Sheet Embedded in a Porous Medium with Radiation and Slip Impacts." Mathematics 9, no. 8 (2021): 878. https://doi.org/10.3390/math9080878 